ISSN: $2338-4794$

Vol.6. No. 3 Sept.- Des. 2018

\title{
PENGARUH PEMAHAMAN MAHASISWA AKUNTANSI DAN INTEGRASI IFRS KE DALAM PERKULIAHAN TERHADAP KOMPETENSI IFRS
}

\author{
Ahmad Basid Hasibuan 1) \\ 1) Dosen Universitas Darma Persada \\ basid_unsada@yahoo.co.id \\ Widyah Nirmala Vanyaseshi ${ }^{2)}$ \\ 2) Mahasiswa Universitas Darma Persada \\ vanyaseshi@gmail.com
}

\begin{abstract}
This study aims to analyze and provide empirical evidence regarding the influence of evaluation of accounting student's understanding of IFRS in facing global market in accounting field related to IFRS competence, dan IFRS integration on college. The population in this study are accounting students of Darma Persada University, questionnaires are distributed as many as 143 and questionnaires that can be used as much as 133. Data analysis techniques with multiple linear regression method. The result indicate that the evaluation of the student's understanding on IFRS and The IFRS integration on college has a positive and significant influence on the IFRS competence
\end{abstract}

Keywords : IFRS Competence, evaluation of student's understanding of IFRS, IFRS integration on college, global market in accounting field.

\section{PENDAHULUAN}

Penerapan IFRS sudah menjadi keharusan bagi setiap negara yang tetap ingin ikut terlibat dalam pencaturan dunia internasional. Amerika adalah salah satu negara yang yang akan menerapkan IFRS pada tahun 2014. Negara Indonesia pun tentunya tidak ingin ketinggalan dalam adopsi IFRS ini. Jika negara Indonesia tidak menerapkan IFRS maka perusahaan - perusahaan asing multinasional yang ada di Indonesia akan menarik investasinya dan perusahaan - perusahaan Indonesia multinasional tidak akan dapat bersaing dengan perusahaan - perusahaan multinasional lainnya. Adopsi di Indonesia dilakukan oleh Ikatan Akuntan Indonesia (Caroline dkk, 2012).

Pengetahuan yang baik akan IFRS akan memberikan beberapa keuntungan seperti : (1) performa yang lebih baik pada ujian sertifikasi Certified Public Accountant (CPA exam), dimana pertanyaan mengenai IFRS akan dimuat pada test tersebut. (2) kesempatan yang lebih besar untuk bekerja pada perusahaan multinasional baik accounting firms maupun non accounting firms (James, 2010). Kantor Akuntan Publik big four bahkan mensyaratkan karyawan yang baru untuk paham IFRS, sedangkan KAP regional juga mengharapkan karyawan mengetahui standar tersebut pada suatu level tertentu. Lulusan akuntansi yang memiliki pengetahuan yang baik terhadap IFRS memiliki keunggulan kompetitif saat rekruitmen karyawan ( McGee, 2012).

Perguruan tinggi akuntansi memiliki peranan untuk mempersiapkan lulusannya agar memahami IFRS dengan baik. Terkait dengan perubahan standar yang sedang terjadi, mahasiswa harus dibekali dengan IFRS, meskipun mereka belum tentu akan bekerja di perusahaan go public setelah lulus S1 akuntansi. Hal ini menyebabkan lembaga pendidikan akuntansi harus menyiapkan mereka agar siap menghadapi perubahan (Herawati, 2011).

Penelitian - penelitian mengenai evaluasi akademisi, khususnya mahasiswa terhadap implementasi IFRS dalam dunia 
pendidikan cenderung lebih sedikit dibandingkan dengan penelitian mengenai dampak IFRS bagi perusahaan dan pasar saham (Pulungan, 2013). Penelitian yang telah dilakukan di Amerika antara lain dilakukan oleh James dan Blaszcynski (2010), menunjukkan mahasiswa tidak yakin akan tingkat pengetahuan IFRS, walaupun mereka setuju bahwa pembelajaran IFRS adalah hal yang penting. Hal ini menunjukkan sebenarnya mahasiswa mempunyai kemauan untuk belajar dan memiliki serta kompetensi mengenai IFRS. (Chiang 2013), menemukan bahwa IFRS kurang terintegrasi dalam kurikulum di Amerika Serikat. Selama ini, mahasiswa sudah terbiasa difokuskan pada US GAAP (Generally Accepted Accounting Principles). Berdasarkan survei, sebagian besar mahasiswa mengatakan bahwa pengenalan IFRS baru dimulai pada saat mata kuliah akuntansi keuangan menengah.

Berdasarkan pada penelitian penelitian terdahulu, dapat disimpulkan sebagian besar mahasiswa jurusan akuntansi menyadari bahwa kompentensi IFRS dibutuhkan dalam dunia kerja, namun mahasiswa belum memiliki kepercayaan diri terhadap pemahaman IFRS yang akan digunakan di dalam dunia kerja di bidang akuntansi. Kondisi yang kini terjadi adalah tahap konvergensi IFRS telah memasuki implementasi IFRS ke dalam PSAK yang berlaku, dan terus disesuaikan dari waktu ke waktu sehingga mahasiswa akuntansi harusnya memiliki pemahaman yang baik mengenai IFRS agar timbul kepercayaan diri saat bersaing dalam dunia kerja di bidang akuntansi,

Penelitian ini dilakukan kembali untuk melanjutkan penelitian - penelitian terdahulu yang membahas mengenai persepsi mahasiswa terhadap IFRS. Penelitian bukan hanya ingin melihat pandangan mahasiswa namun juga mengevaluasi pemahaman mahasiswa akuntansi setelah IFRS diimplementasikan ke dalam mata kuliah khususnya di Universitas Darma Persada

\section{LANDASAN TEORI}

\section{Evaluasi}

Evaluasi oleh Arifin (2013) didefinisikan sebagai suatu proses untuk menggambarkan peserta didik dan menimbangnya dari segi nilai dan arti. Arikunto (2013) secara singkat mendefinisikan kegiatan evaluasi sebagai kegiatan yang meliputi pengukuran dan penilaian. Berdasarkan definisi - definisi tersebut, dapat disimpulkan evaluasi berkaitan dengan nilai dan arti.

Dari definisi evaluasi yang telah dijabarkan, sangat jelas bila istilah evaluasi berbeda dengan istilah penilaian. Istilah evaluasi digunakan untuk konteks yang lebih luas, selain itu dapat dilaksanakan oleh pihak eksternal maupun internal, sedangkan penilaian digunakan untuk konteks yang lebih sempit, bersifat kualitatif dan sering menggunakan ukuran baik buruk. Istilah penilaian juga memiliki kecenderungan dilaksanakan oleh orang orang internal. Evaluasi dapat disimpulkan sebagai kegiatan pengolahan, pegukuran dan penilaian suatu kondisi dengan data yang relevan yang bermanfaat untuk memberikan pilihan alternatif dalam pengambilan keputusan.

\section{Kepemahaman IFRS}

Kamus Besar Bahasa Indonesia menyatakan bahwa 'paham' memiliki arti pandai atau mengerti benar sedangkan "pemahaman" adalah proses, cara, perbuatan memahami atau memahaman. Ernest Hilgard (dalam Wirawan, 2012) membagi pemahaman menjadi enam yaitu, (1) Pemahaman yang dipengaruhi kemampuan dasar (2) Pemahaman yang dipengaruhi pengalaman belajar yang lalu (3) pemahaman tergantung kepada pengaturan situasi (4) pemahaman didahului oleh usaha coba - coba, (5) Belajar dengan pemahaman dapat diulang, 
(6) pemahaman dapat diaplikasikan bagi pemahaman situasi lain.

Berdasarkan pengertian tersebut dapat disimpulkan bahwa pemahaman adalah kemampuan seseorang untuk mengerti suatu topik atau informasi setelah mendapatkan pembelajaran atau informasi dari sumber - sumber yang ada. Pemahaman IFRS merupakan suatu kemampuan seseorang untuk mengenal, mengerti dan memahami standard dan ketentuan - ketentuan yang berlaku IFRS. Tingkat pemahaman IFRS ini dapat diukur dari sejauh mana seseorang mengetahui dan mengerti IFRS.

\section{Kompetensi IFRS}

Kompetensi dalam Kamus Besar Bahasa Indonesia berarti kemampuan menguasai gramatika suatu bahasa secara abstrak atau batiniah. Kompetensi mahasiswa mengenai IFRS dikhususkan pada kompetensi dalam memahami dan mengaplikasikan IFRS. Kategori pemahaman dan aplikasi kompetensi IFRS diambil dari penelitian Yoon, Vedd \& Jones (2013) taksonomi bloom yang telah direvisi oleh Pulungan (2013) sesuai dengan kebutuhan penelitian.

Tabel 1. Taksonomi Bloom Direvisi

\begin{tabular}{|c|c|c|}
\hline $\begin{array}{c}\text { Tujuan Pembelajaran } \\
\text { Mahasiswa }\end{array}$ & $\begin{array}{c}\text { Kategori } \\
\text { Taksonomi Bloom } \\
\text { yang Direvisi }\end{array}$ & $\begin{array}{c}\text { Level } \\
\text { Taksonomi }\end{array}$ \\
\hline $\begin{array}{l}\text { Mahasiswa } \\
\text { menjelaskan perbedaan } \\
\text { antara principles }- \text { based } \\
\text { dan rule based }\end{array}$ & Pemahaman & 2 \\
\hline $\begin{array}{l}\text { Mahasiswa mampu } \\
\text { membandingkan persamaan } \\
\text { dan perbedaan antara IFRS } \\
\text { dan PSAK berbasis IFRS }\end{array}$ & Pemahaman & 2 \\
\hline $\begin{array}{l}\text { Mahasiswa mampu } \\
\text { menjelaskan perkembangan } \\
\text { konvergensi IFRS di } \\
\text { Indonesia saat ini }\end{array}$ & Pemahaman & 2 \\
\hline $\begin{array}{lr}\text { Mahasiswa } & \text { mampu } \\
\text { menjelaskan } & \text { proses } \\
\text { penetapan standar } & \text { IFRS }\end{array}$ & Pemahaman & 2 \\
\hline $\begin{array}{lr}\text { Mahasiswa } & \text { mampu } \\
\text { membaca dan mengerti } \\
\text { laporan keuangan } \\
\text { IFRS }\end{array}$ & Aplikasi & 3 \\
\hline $\begin{array}{lrr}\text { Mahasiswa } & \text { mampu } \\
\text { mencatat } & \text { transaksi } \\
\text { keuangan } & \text { sesuai } & \text { dengan } \\
\text { IFRS } & & \end{array}$ & Aplikasi & 3 \\
\hline $\begin{array}{l}\text { Mahasiswa mampu } \\
\text { membuat laporan keuangan } \\
\text { berbasis IFRS }\end{array}$ & Aplikasi & 3 \\
\hline
\end{tabular}




\section{Kerangka Pemikiran}

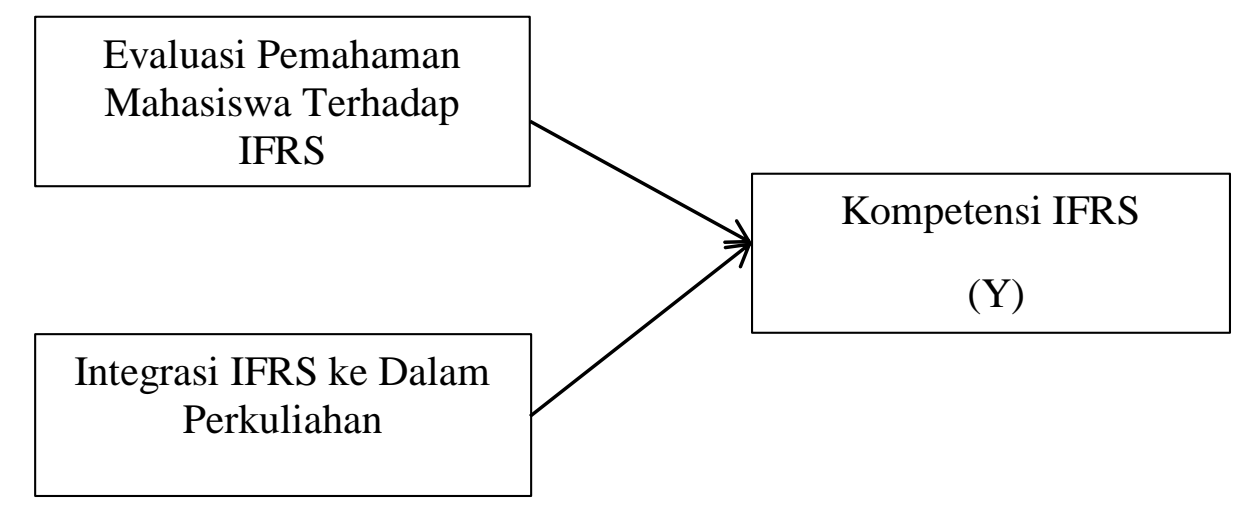

Evaluasi merupakan kegiatan pengolahan, pengukuran dan penilaian suatu kondisi dengan data yang relevan. Evaluasi pemahaman mahasiswa mengenai IFRS dalam penelitian ini dikaitkan dengan kesiapan mahasiswa terhadap IFRS saat pada saat ini dan pada saat menyelesaikan pendidikan $\mathrm{S}-1$, serta dalam menghadapi dunia kerja di bidang akuntansi baik dari segi kompetensi IFRS yang dimiliki, kemudahan mendapatkan pekerjaan, gaji yang akan didapatkan dan jenjang karir.

Integrasi IFRS ke dalam perkuliahan diukur dari pengetahuan dan pemahaman mahasiswa akan perkembangan standar akuntansi dan penerapan IFRS ke dalam melalui buku - buku dan bahan ajar yang digunakan dan disampaikan pada saat perkuliahan.

Kompetensi mahasiswa dikhususkan pada kemampuan mahasiswa dalam memahami dan mengaplikasikan IFRS. Pemahaman dan pengaplikasian menggunakan pertanyaan yang digunakan oleh Yoon, Veed, \& Jones (2013) yang telah dimodifikasi dan didasarkan dengan pada tujuan pembelajaran sesuai dengan taksonomi bloom yang direvisi (Pulungan, 2013).

\section{Hipotesis Penelitian}

Hipotesis adalah pernyataan yang diterima secara sementara sebagai suatu kebenaran sebagaimana adanya, pada saat fenomena dikenal dan merupakan dasar kerja serta panduan - panduan dalam verifikasi (Nasir, 2014).

Hipotesis 1

$\mathrm{H}_{0} \quad$ : Tidak terdapat pengaruh langsung antara evaluasi pemahaman mahasiswa mengenai IFRS dalam menghadapi dunia kerja bidang akuntansi terhadap kompetensi mahasiswa dalam IFRS

$\mathrm{H}_{\mathrm{a}}$ : Terdapat pengaruh langsung antara evaluasi pemahaman mahasiswa mengenai IFRS dalam menghadapi dunia kerja bidang akuntansi terhadap kompetensi mahasiswa dalam IFRS

Hipotesis2

$\mathrm{H}_{0} \quad$ : Tidak terdapat pengaruh langsung antara integrasi IFRS ke dalam perkuliahan terhadap kompetensi mahasiswa dalam IFRS

$\mathrm{H}_{\mathrm{a}} \quad$ : Terdapat pengaruh langsung antara integrasi IFRS ke dalam perkuliahan terhadap kompetensi mahasiswa dalam IFRS

\section{METODE PENELITIAN}

Analisis data yang digunakan adalah uji asumsi klasik yang terdiri dari uji normalitas, uji multikolinearitas dan uji heteroskedastisitas. Uji hipotesis yang terdiri dari uji regresi linear berganda, uji $t$ dan uji koefisien determinasi $\left(\mathrm{R}^{2}\right)$. 


\section{Hasil Penelitian}

Berdasarkan 133 kuesioner yang dianalisis, hasil pengujian validitas menunjukkan nilai butir koreksi - korelasi total dari variabel evaluasi pemahaman mahasiswa akuntansi $\left(\mathrm{X}_{1}\right)$, variabel integrasi IFRS ke dalam perkuliahan $\left(\mathrm{X}_{2}\right)$ dan variabel kompetensi IFRS (Y) lebih besar dari $\mathrm{r}_{\text {hitung }} \mathrm{N}_{133}$, dengan demikian instrument penelitian valid.

Hasil pengujian reabilitas dengan menggunakan Cronbach Alpha untuk variabel evaluasi pemahaman mahasiswa akuntansi $\left(X_{1}\right)$ sebesar 0,827 , variabel integrasi IFRS ke dalam perkuliahan $\left(\mathrm{X}_{2}\right)$ sebesar 0,701 dan variabel kompetensi IFRS (Y) sebesar 0,862. Seluruh hasil menunjukkan bahwa nilai Cronbach-Alpha $>0,70$ sehingga instrument dapat dinyatakan reliable.

\section{1.) Uji Asumsi Klasik}

\section{a. Uji Normalitas}

Berdasarkan hasil uji normalitas tersebut, diperoleh nilai asymp.sig (2 tailed) sebesar 0,200 yang berarti lebih besar dari 0,05 maka dapat disimpulkan bahwa data yang digunakan dalam penelitian ini memiliki distribusi normal

\section{b. Uji Multikolinearitas}

Variabel evaluasi pemahaman mahasiswa akuntansi dan variable integrasi IFRS ke dalam perkuliahan mempunyai nilai tolerance sebesar 0,760 dan VIF sebesar 1,316 dimana nilai tolerance lebih besar dari 0,1 dan nilai VIF lebih kecil dari 10. Sehingga dapat diambil kesimpulan bahwa penelitian ini tidak terjadi multikolinearitas

\section{c. Uji Heteroskedastisitas}

Hasil uji heteroskedastisitas dengan uji glejser nilai signifikan variabel evaluasi pemahaman mahasiswa adalah 0,888 yaitu nilainya lebih besar dari 0,05 atau $(0,888>$ $0,05)$. Nilai signifikan variabel integrasi IFRS ke dalam perkuliahan adalah 0,290 yaitu nilainya lebih besar dari 0,05 atau $(0,290>0,05)$ maka tidak terdapat adanya gejala heteroskedastisitas.

\section{2.) Uji Hipotesis}

Persamaan garis regresinya adalah sebagai berikut :

$$
\mathrm{Y}=0,001+0,000 \mathrm{X}_{1}+0,000 \mathrm{X}_{2}+e
$$

Nilai koefisien regresi variabel evaluasi $\left(b_{1}\right)$ bernilai positif sebesar 0,169 . Hal ini berarti evaluasi pemahaman mahasiswa terhadap IFRS berpengaruh positif terhadap kompetensi mahasiswa IFRS. Nilai koefisien regresi evaluasi pemahaman mahasiswa akuntansi sebesar 0,169 yang berarti jika variabel evaluasi meningkat 1 kali maka kompetensi mahasiswa IFRS akan meningkat 0,169 kali.

Nilai koefisien regresi variabel integrasi $\left(b_{2}\right)$ bernilai positif sebesar 0,383. Hal ini berarti bahwa integrasi IFRS ke dalam perkuliahan berpengaruh positif terhadap kompetensi IFRS. Nilai koefisien regresi integrasi IFRS ke dalam perkuliahan sebesar 0,383 yang berarti jika variabel integrasi IFRS ke dalam perkuliahan meningkat sebesar 1 kali, maka kompetensi IFRS akan meningkat sebesar 0,383 kali.

\section{Uji t}

Variabel evaluasi pemahaman mahasiswa terhadap IFRS $\left(\mathrm{X}_{1}\right)$ memiliki $t_{\text {hitung }}$ sebesar 2,777 dan $t_{\text {tabel }}$ sebesar 1,970 yang artinya $t_{\text {hitung }} X_{1}>t_{\text {tabel }}$ atau 2,777 > 1,970. Variabel evaluasi pemahaman mahasiswa terhadap IFRS memiliki tingkat signifikansi yang lebih kecil dari 0,50 atau $(0,006<0,05)$. Hal ini menunjukkan evaluasi pemahaman mahasiswa mengenai IFRS berpengaruh secara signifikan terhadap kompetensi IFRS atau dengan kata lain hipotesis pertama $\mathrm{H}_{0}$ ditolak dan $\mathrm{H}_{\mathrm{a}}$ diterima. 
Variabel integrasi $\left(\mathrm{X}_{2}\right)$ memiliki $t_{\text {hitung }}$ sebesar 4,143 dan $t_{\text {tabel }}$ sebesar 1,970 yang artinya $t_{\text {hitung }} \mathrm{X}_{2}>\mathrm{t}_{\text {tabel }}$ atau 4,143>1,970. Variabel integrasi IFRS ke dalam perkuliahan memiliki tingkat siginifikansi yang lebih kecil dari 0,05 atau $(0,000<0,05)$. Hal ini menunjukkan integrasi IFRS ke dalam perkuliahan berpengaruh secara signifikan terhadap kompetensi IFRS atau dengan kata lain hipotesis kedua $\mathrm{H}_{0}$ ditolak dan $\mathrm{H}_{\mathrm{a}}$ diterima.

Koefisien determinasi $\left(\mathrm{R}^{2}\right)$ mengukur seberapa jauh kemapuan model dalam menerangkan variasi variabel dependen. Nilai koefisien determinasi adalah antara nol dan satu.

Koefisien determinasi yang disesuaikan (adjusted R Square) sebesar 0,257 artinya variabel evaluasi pemahaman mahasiswa terhadap IFRS dan integrasi IFRS ke dalam perkuliahan terhadap variabel kompetensi IFRS sebesar $25,7 \%$ sedangkan sisanya sebesar $74,3 \%$ disumbangkan oleh variabel lain yang tidak terdapat dalam penelitian ini.

\section{HASIL PENELITIAN DAN PEMBAHASAN}

Berdasarkan hasil analisis data yang telah diuraikan sebelumnya, pembahasan dan pemecahan masalah akan diuraikan sebagai berikut : (1). Evaluasi Pemahaman mahasiswa mengenai IFRS dalam menghadapi dunia kerja di bidang akuntansi memiliki pengaruh positif dan signifikan terhadap kompetensi mahasiswa dalam IFRS.Hasil penelitian menunjukan bahwa variabel evaluasi pemahaman ma hasiswa terhadap IFRS memiliki pengaruh yang positif dan signifikan terhadap variabel kompetensi IFRS. Hasil penelitian ini konsisten atau sama dengan hasil penelitian yang dilakukan oleh Al Mutairi, et all (2017). Hasil penelitiannya adalah variabel manfaat mempelajari IFRS terkait dengan dunia kerja berpengaruh positif dan signifikan terhadap pengetahuan mengenai IFRS. Dari hasil tersebut, dapat ditarik kesimpulan bahwa sebagian besar mahasiswa akuntansi Universitas Darma Persada menyadari pentingnya pengetahuan tentang IFRS dalam menghadapi dunia kerja di bidang akuntansi terkait dengan kompetensi mahasiswa sendiri sehingga dapat memperoleh gaji dan jenjang karir yang lebih baik serta memiliki keunggulan dalam mengikuti ujian profesi akuntan. IFRS telah digunakan oleh perusahan yang go public, BUMN, perusahaan penghimpun dana dari masyarakat (perbankan, asuransi, dana pensiun lembaga keuangan) dan perusahaan lainnya yang secara suka rela menggunakan IFRS sebagai standar pelaporan keuangan. Pemahaman dan pengetahuan mahasiswa tentang IFRS akan dapat meningkatkan reputasi dan prestasi dalam mencapai karir yang lebih baik. (2). Integrasi IFRS ke dalam Perkuliahan memiliki pengaruh positif dan signifikan terhadap kompetensi mahasiswa dalam IFRS. Hasil penelitian menunjukan bahwa variabel integrasi IFRS ke dalam perkuliahan memiliki pengaruh positif dan signifikan terhadap variabel kompetensi IFRS. Penelitian ini konsisten atau sama dengan penelitian yang dilakukan oleh Nugraheni dan Sulistiawati (2012) . Hasil penelitiannya adalah variabel minat berpengaruh positif dan signifikan terhadap tingkat pemahaman IFRS. Dapat disimpulkan bahwa adanya penerapan IFRS ke dalam mata kuliah tertentu terutama pengantar akuntansi, akuntansi keuangan, akuntansi keuangan lanjutan, dan teori akuntansi dapat meningkatkan kompetensi mahasiswa dalam memahami dan mengaplikasikan IFRS. Persepsi mahasiswa tentang IFRS yang terintegrasi ke beberapa mata kuliah memiliki pengaruh yang kuat, dapat dilihat dari pandangan mahasiswa mengenai kompetensi IFRS yang dimiliki akan terkait erat dengan kompetensi di bidang akuntansi. Dosen perlu meng-update 
tentang standar akuntansi dalam bahan, materi atau modul yang akan disampaikan kepada mahasiswa, sehingga ada integrasi antara materi yang diajarkan dengan mata kuliah tersebut yang berkaitan dengan standar akuntansi yang berlaku dan membantu mahasiswa dalam memahami standar akuntansi. Mahasiswa sendiri harus aktif untuk mencari referensi untuk lebih memahami IFRS melalui buku, jurnal, dan standar akuntansi.

\section{KESIMPULAN DAN SARAN}

Berdasarkan hasil analisis dan pembahasan mengenai pengaruh evaluasi pemahaman mahasiswa akuntansi Universitas Darma Persada dan Integrasi IFRS ke dalam Perkuliahan terhadap Kompetensi IFRS dalam Menghadapi Dunia Kerja di Bidang Akuntansi, maka dapat ditarik beberapa kesimpulan sebagai berikut : (1). Variabel evaluasi pemahaman mahasiswa terhadap IFRS memiliki pengaruh positif dan signifikan terhadap variabel kompetensi IFRS. Penelitian ini sama dengan penelitian sebelumnya yaitu manfaat mempelajari IFRS berpengaruh positif signifikan terhadap pengetahuan mengenai IFRS. (2). Variabel integrasi IFRS ke dalam perkuliahan $\left(\mathrm{X}_{2}\right)$ memiliki pengaruh positif dan signifikan terhadap variabel kompetensi IFRS (Y). Penelitian ini sama dengan penelitian sebelumnya yaitu minat berpengaruh positif dan signifikan terhadap tingkat pemahaman IFRS.

Dengan adanya keterbatasan penelitian ini, maka dapat disimpulkan beberapa saran sebagai berikut : (1). Adapun penelitian ini memiliki keterbatasan tentang faktor pemahaman mahasiswa yang didorong oleh adanya peran dosen dalam menyampaikan materi IFRS kepada mahasiswa belum dilakukan dalam penelitian ini. Bagi penelitian berikutnya, yang berminat untuk meneliti topik yang serupa hendaknya bisa menambahkan variable tersebut. (2). Keterbatasan lainnya adalah kurikulum yang terintegrasi dalam mata kuliah belum dibahas dalam penelitian ini, diharapkan untuk selanjutnya bisa menambah jumlah variabel sehingga dapat menambah daftar pernyataan dalam kuesioner secara lebih lengkap terkait dengan integritas terhadap matakuliah dan kompetensi IFRS. (3). Disarankan juga agar menambahkan sampel penelitian dengan jumlah perguruan tinggi yang menjadi sample dalam penelitian ini karena hanya terbatas satu perguruan tinggi saja

\section{DAFTAR PUSTAKA}

Al Mutairi, Abdullah, Nesser, Kamal Al Duwaila, Nabi 2017. Student's Attitude Towards the Adoption of International Financial Reporting Standards (IFRS) in Kuwait. Asian Social Journal Vol 13, No 5.

Arifin, Zaenal, 2013. Evaluasi Pembelajaran. Bandung : Rosdakarya.

Arikunto, Suharsimi. 2013. Dasar-Dasar Evaluasi Pendidikan. Jakarta : Bumi Aksara.

Chiang, Bea. IFRS in the Accounting Curriculum - Implications from Differrent Perspectives. International Business and Management Vol. 6, No 2, 2013, pp. $1-8$.

Carolina,Verani, Martusa, Riki dan Meythi. 2012. Harmonisasi Implementasi International Financial Reporting Standards terhadap Sistem Hukum di Indonesia. Prosiding Seminar Nasional "Problematika Hukum dalam Implementasi Bisnis dan Investasi (Perspektif Multidisipliner) "(http://majour.maranatha.edu/index. $\mathrm{php} / \mathrm{maksi} /$ article/view/620

Herawati, Nyoman Trisna Konvergensi International Financial Reporting Standards (IFRS) dan Implikasinya Terhadap Pembelajaran Akuntansi Pengantar di Perguruan Tinggi. 
ejournal.undiksha.ac.id/index.php/JJ

A/article/view/308

James, M.L., Blaszczynski, C. 2010.

Accounting Students Perceptions Of International Financial Reporting Standards. Journal For Global Business, vol. 10, no.2, pp. $37-49$.

McGee, J Bandyopadhay. 2009. A Contribution To Practice : Exploring The Curriculum Impactof IFRS US GAAP Convergence (search.proquest.com).

Nugraheni, Diana ., Sulistiawati, Andriani Ika . 2012. Faktor - faktor yang Mempengaruhi

Tingkat Pemahaman IFRS. (journal.usm.ac.id)

Pulungan, Andrey Hasiholan 2013. Persepsi Mahasiswa Terhadap IFRS dan Kompetensi Mahasiswa dalam Memahami dan Mengaplikasikan IFRS. Jurnal Akuntansi \& Manajemen Vol 8 No.1 Juni 2013.

Yoon, S.W.,Vedd, R., Jones, C.G., 2013, IFRS Knowledge, Skill, and Abilities: A follow-up Study of Employer Expectations for Undergraduate Accounting Majors, Journal of Education for Business, Vol. 88 No.6 pp.352-360.

Wirawan, 2012, Evaluasi Teori, Model, Standar, Aplikasi, dan Profesi, Depok, PT Rajawali Grafindo Persada. 